\title{
Uptake of long acting reversible contraception following integrated couples HIV and fertility goal-based family planning counselling in Catholic and non-Catholic, urban and rural government health centers in Kigali, Rwanda
}

Jeannine Mukamuyango ${ }^{1}$, Rosine Ingabire ${ }^{1}$, Rachel Parker ${ }^{2}$, Julien Nyombayire ${ }^{1}$, Andrew Abaasa ${ }^{3,4}$, Gershim Asiki ${ }^{4}$, Sarah Rae Easter ${ }^{5}$, Kristin M. Wall ${ }^{6}$, Laetitia Nyirazinyoye ${ }^{7}$, Amanda Tichacek ${ }^{2}$, Nadine Kaslow ${ }^{8}$, Matt A. Price ${ }^{9,10}$, Susan Allen ${ }^{2^{*}}$ (D) and Etienne Karita ${ }^{1}$

\begin{abstract}
Background: When integrated with couples' voluntary HIV counselling and testing (CVCT), family planning including long acting reversible contraceptives (LARC) addresses prongs one and two of prevention of mother-tochild transmission (PMTCT).

Methods: In this observational study, we enrolled equal numbers of HIV concordant and discordant couples in four rural and four urban clinics, with two Catholic and two non-Catholic clinics in each area. Eligible couples were fertile, not already using a LARC method, and wished to limit or delay fertility for at least 2 years. We provided CVCT and fertility goal-based family planning counselling with the offer of LARC and conducted multivariate analysis of clinic, couple, and individual predictors of LARC uptake.

Results: Of 1290 couples enrolled, 960 (74\%) selected LARC: Jadelle 5-year implant (37\%), Implanon 3-year implant (26\%), or copper intrauterine device (IUD) (11\%). Uptake was higher in non-Catholic clinics $85 \%$ vs. 63\% in Catholic clinics, $p<0.0001$ ), in urban clinics (82\% vs. $67 \%$ in rural clinics, $p<0.0001$ ), and in HIV concordant couples (79\% vs. $70 \%$ of discordant couples, $p=.0005$ ). Religion of the couple was unrelated to clinic religious affiliation, and uptake was highest among Catholics (80\%) and lowest among Protestants (70\%) who were predominantly Pentecostal. In multivariable analysis, urban location and non-Catholic clinic affiliation, Catholic religion of woman or couple, younger age of men, lower educational level of both partners, non-use of condoms or injectable contraception at (Continued on next page)
\end{abstract}

\footnotetext{
* Correspondence: sallen5@emory.edu

${ }^{2}$ Rwanda Zambia HIV Research Group, Department of Pathology \& Laboratory Medicine, School of Medicine, Emory University, Atlanta, GA, USA Full list of author information is available at the end of the article
} 
(Continued from previous page)

enrollment, prior discussion of LARC by the couple, and women not having concerns about negative side effects of implant were associated with LARC uptake.

Conclusions: Fertility goal-based LARC recommendations combined with couples' HIV counselling and testing resulted in a high uptake of LARC methods, even among discordant couples using condoms for HIV prevention, in Catholic clinics, and in rural populations. This model successfully integrates prevention of HIV and unplanned pregnancy.

\section{Plain English summary}

Preventing unplanned pregnancy is an important health and economic goal for Africa. Contraceptive methods that don't require remembering to take a pill every day or schedule an injection every two to 3 months are less likely to fail. Two of these methods, the copper intrauterine device (IUD) and the hormonal implant, are effective for 12 years and 5 years, respectively. They can also be removed if a pregnancy is desired. Many African women could benefit from access to these long acting reversible contraceptive (LARC) methods but they require trained nurses to insert and male partners are usually not familiar with them. In government clinics in Kigali, the capital of Rwanda, couples who expressed a desire to wait at least 2 years before becoming pregnant were educated together about LARC methods first in a group and then individually with a nurse trained to insert LARC methods. The impact was substantial with $74 \%$ of 1290 couples requesting a LARC method. LARC methods are effective and affordable and programs that expand access are critically needed. Testing couples together for HIV is also a highly effective HIV prevention strategy and Rwanda is the only country in Africa that has nationalized this service in all government clinics. By combining: Couples' voluntary HIV counseling and testing (CVCT) with Couples' family planning counseling (CFPC), those that have one $\mathrm{HIV}$-positive $(\mathrm{HIV}+)$ and one HIV-negative (HIV-) partner can be advised to use condoms for HIV prevention plus a LARC method for more effective pregnancy prevention.

\section{Background}

Rwanda has the highest population density in continental Africa and a high burden of HIV, highlighting the need to mutually leverage HIV and family planning (FP) efforts. The modern contraceptive prevalence in married Rwandan women is estimated at 53.2\% in 2015, with oral contraceptive pills (OCP) and progesterone-based injectables (usually depo-medroxyprogesterone acetate: DMPA or Depo-Provera) reported by most users (World Bank: https://data.worldbank.org/indicator/). With proactive social marketing and community-based distribution of OCP and DMPA, World Bank estimates show TFR has decreased from 8.5 in 1980 to 3.9 in 2015. To safeguard economic development, the Government of Rwanda (GoR) has set a goal of three or less for the total fertility rate (TFR).

For women who wish to end childbearing or delay pregnancy for more than 2 years, the most effective long-acting reversible contraceptives (LARC) available in Rwanda- the copper intrauterine device (IUD) and the hormonal contraceptive implant - are not subject to problems of user error or re-supply, and they are more effective and cost-efficient over the long term [1]. Once inserted by a clinician, the copper IUD is approved for up to 12 years of use. Contraceptive implants provide effective contraceptive coverage for 3 (Implanon) to 5 years (Jadelle) [2-5]. Though the majority of Rwandan couples want to limit or delay childbearing [6], few nurses are trained to insert LARC and as a result relatively few clients know about these methods [7, 8]. Lastly, many government health centers in Rwanda are affiliated with the Catholic Church and do not offer contraception.

The literature on HIV and FP integration includes interventions targeting providers [9-12], HIV+ patients [13-15], and discordant couples [16, 17] as well as efforts to enhance male involvement [18-20]. In heterosexual populations with a high prevalence of HIV, an important target audience for HIV and FP services is couples who can benefit from joint services [21-23]. Centers that provide integrated services report that clients vastly prefer this model [24, 25]. Integration models have added FP counseling and methods for patients in HIV care clinics [26-30] and conversely provided HIV testing and referral to FP clients [31-33]. However, historical, philosophical and structural differences in the fields of FP and HIV pose obstacles to integration both in the United States and developing countries [34]. Staff tend to see the two categories as distinctly different [35]. Service delivery styles also differ: FP clinics often rely on a fact-giving approach, while HIV-testing services emphasize client-centered counseling [36]. 'Dual method' use - condoms for HIV/STI prevention PLUS a longer-acting method for pregnancy prevention - is the best course of action [34], but often condom use is emphasized as an alternative rather than adjunctive method. Lastly, at the facility level, numerous studies 
confirm that logistical obstacles including under-staffing, lack of space, vertical service silos and sub-optimal training remain major challenges [37-45].

Our previous work has shown that LARC training and promotion in Kigali government clinics increased the proportion of family planning clients who requested a LARC method from $<2 \%$ in 2009 to $17 \%$ in 2014 [46], confirming that LARC are acceptable to women seeking contraception. We have also shown that limited knowledge of LARC methods among men [7] and poor communication about fertility goals within the couple [47] can be overcome through joint counseling, leading to LARC uptake [6]. While these advances are promising, women and couples at risk of unplanned pregnancy in Rwanda continue to face limited information and access, particularly in rural areas and in clinics with Catholic affiliation [48]. The impact of this is reflected in the (illegal) abortion rate of 25/1000 women annually [49].

Similar to other African countries [50-53], there is consensus among stakeholders in Rwanda that HIV and family planning (FP) services should be integrated [54]. The Government of Rwanda strongly supports access to the full range of contraceptive options [55] and provides free therapeutic antiretrovirals (ARV) and PMTCT for HIV [56]. Rwanda provides a unique context in which to evaluate HIV-FP integration: since 2013, two-thirds of new HIV infections in marriage have been prevented by nationalized Couples Voluntary HIV Counseling and Testing (CVCT) in antenatal clinics [57-59]. This addresses prong 1 of prevention of mother-to-child transmission (PMTCT) - (prevention of HIV in childbearing women). Prong 2 of PMTCT focuses on prevention of unplanned pregnancies among couples with or at risk of HIV. Integrated services that emphasize effective contraception and dual method use would maximize both Prongs $1 \& 2$ of PMTCT [60] and cost less per HIV infection averted than Prongs 3 and 4 that involve ARVs [61-64]. However, in Rwanda, CVCT is not currently offered to non-pregnant couples, and contraception is provided to women in family planning clinics but not elsewhere.

We present here the results of an integrated program providing 1) joint HIV testing and family planning counseling; 2) fertility-goal based LARC promotion and provision and 3) training, supplies and protected time for service providers. This program focuses on both supply and demand addressed simultaneously with skills training for providers, education for clients, and adequate human resources and space. To explore potential obstacles and facilitators, we compare LARC uptake in relation to rural/urban clinic location, Catholic/nonCatholic clinic affiliation, couple HIV serostatus and other participant characteristics.

\section{Methods}

\section{Study design and setting}

This observational study of the effect of an intervention on LARC uptake [65] was conducted by the Projet San Francisco (PSF), a part of the Rwanda Zambia HIV Research Group (RZHRG) established in 1986 and affiliated with the Emory University School of Medicine, in collaboration with the Ministry of Health $(\mathrm{MoH})$ of Rwanda. We selected eight health centers in and around the city of Kigali offering CVCT in antenatal clinics (ANC), infant vaccination, quarterly follow-up of HIV sero-discordant couples, and HIV care and antiretroviral treatment (ART) services. We chose two health centers in each of the following categories, ensuring that no catchment areas overlapped: urban Catholic, urban nonCatholic, rural Catholic, and rural non-Catholic. Catholic-affiliated clinics do not provide family planning but refer to nearby health posts established by the $\mathrm{MoH}$ for that purpose. Clinic nurses screened couples in outpatient departments and referred eligible and interested couples to the study. All activities and data collection took place at the government clinics.

To ensure that clinic staff providing HIV and/or FP services were not distracted from other responsibilities, we hired them to work for the study while they were off duty. Training in counseling and LARC insertion and removal was provided with certificates for successful trainees. This protected staff from overburden and patients from unnecessary delays. Clinic stocks of LARC supplies including insertion kits and autoclaves were assessed and necessary provisions provided as needed.

\section{Study population}

We enrolled heterosexual cohabiting couples in which the woman was aged between 21 and 40 years and the man aged $>=21$; planning to live in Kigali for at least 2 years; both partners were fertile (prior history of pregnancy, no surgical sterilization or hysterectomy); the woman was not pregnant; the couple was not wanting to conceive in the next 2 years; and the woman was not using a LARC method. Our enrollment was targeted to reach 1200 couples equally distributed between concordant HIV positive $(\mathrm{M}+\mathrm{F}+)$, concordant HIV- (M-F-), and discordant $(\mathrm{M}+\mathrm{F}-$ and $\mathrm{M}-\mathrm{F}+)$ between May and December of 2015.

\section{Study procedures}

On the day of enrollment, study counselors conducted group information sessions to read and explain the informed consent document to interested couples. Couples then discussed with a counselor privately and signed a joint informed consent. Interviewers administered a baseline questionnaire to the man and the woman separately to collect data on demographic characteristics, 
obstetric and contraceptive history, fertility goals and knowledge and beliefs about LARC methods. Interviewers used tablet-based data collection with survey CTO. Couples were tested for HIV (two rapid tests according to the national algorithm) [66] and syphilis (RPR, Macro-vue) [67].

\section{Intervention}

While couples were waiting for their serology test results, a group session was conducted by a trained community health worker (CHW) using a flip chart. The $\mathrm{MoH}$ had previously trained Kigali $\mathrm{CHW}$ to distribute OCP and administer injectable contraceptives in their communities. Study nurses provided them with additional LARC information prior to study initiation [68]. The flip chart presented a fertility goal-based approach to contraceptive choice, with the advantages of LARC methods highlighted for this audience of couples wishing to limit or delay pregnancy for at least 2 years. The flip chart illustrated IUD and implant insertion procedures and discussed contraindications and side effects. Jadelle and Implanon Implants and copper IUD (LARC methods available through government procurement) were passed around the group and participants were encouraged to feel them and to ask questions.

Following the group session, nurse-counselors provided HIV and syphilis post-test counseling to both partners together with appropriate treatment and referral. They then asked a series of questions structured to help the couple discuss and agree on fertility goals and decide whether a LARC method would be suitable for them. Couples could choose to have a LARC method inserted immediately or could request a subsequent appointment for insertion.

\section{Measurements}

The main outcome of the study was uptake of any of the LARC (Jadelle, Implanon or IUD) methods on the day of enrollment or any time prior to the follow-up visit scheduled 1 month later. The study primary exposures were rural/urban clinic location, Catholic/non-Catholic clinic affiliation, and couple HIV serostatus. Demographic measures assessed on baseline questionnaire included age, years of cohabitation, number of children, duration of residence in Kigali, literacy in Kinyarwanda, English and French, level of education, income, religious affiliation, and frequency of church attendance. Prior HIV testing history, ART use, contraceptive use and source of information, fertility goals and knowledge, and previous experience or discussion about LARC methods were recorded.

\section{Statistical analysis}

Statistical analysis was performed in SAS v9.4 (Cary, $\mathrm{NC}$ ). The association between the outcome (uptake of LARC) and categorical variables was determined using chi-square or Fisher's exact for categorical variables, and two-tailed t-test was used for continuous variables. Frequencies of responses are shown in Tables as column percent. LARC uptake within response categories are shown in Tables as row percent. Bivariate and multivariate logistic regression models were used to estimate crude and adjusted odds ratios, 95\% confidence intervals (CIs), and $p$-values. An interaction term was included for clinic location and clinic religion based on differences in association with LARC uptake among subgroups. Covariates significant in bivariate models at an alpha of 0.05 were included in the multivariate model following a collinearity assessment; covariates not significant in the multivariate model at an alpha of 0.05 were removed via backwards elimination from the final multivariate model.

\section{Ethical consideration}

Ethical approval was obtained from the National Ethics Committee of Rwanda and the Institutional Review Board at Emory University. All participants signed the approved, informed consent document before enrollment. Participant data was unlinked to identifiers and kept confidential.

\section{Results}

Unless specified, all comparisons mentioned are statistically significant with $p$-values shown in Tables, footnotes or text. Variables not significantly associated with LARC uptake are listed in Table footnotes.

\section{LARC uptake by couple HIV serostatus, urban vs. rural clinic location, and Catholic vs. non-Catholic clinic affiliation (Table 1)}

Of 1691 couples referred from infant vaccination (54\%), follow-up of discordant couples (35\%), HIV care and treatment (9\%) and family planning (2\%) services, 1353 (80\%) were screened and $1290(76 \%)$ were eligible and enrolled.

These included 330 (26\%) HIV concordant negative (M-F-), 327 (25\%) HIV concordant positive $(\mathrm{M}+\mathrm{F}+)$, 319 (25\%) (woman positive partner; $\mathrm{M}-\mathrm{F}+$ ), and 314 (24\%) HIV discordant (man positive partner; $M+F-$ ). Each serotatus was equally distributed among urban Catholic $(n=315,24 \%)$, urban non-Catholic $(n=333$, $26 \%)$, rural Catholic $(n=317,25 \%)$ and rural nonCatholic $(n=325,25 \%)$ clinics.

LARC uptake was higher among concordant (79\%) than among discordant couples $(70 \%)(p=0.0005)$, and among couples with HIV- men (77\%) compared with 
Table 1 LARC uptake by couple serostatus, urban vs.rural location and Catholic vs.non-Catholic clinic affiliation

\begin{tabular}{|c|c|c|c|c|c|c|c|c|c|c|}
\hline & \multicolumn{2}{|c|}{$\begin{array}{l}\text { All Couples } \\
(n=1290)\end{array}$} & \multicolumn{2}{|c|}{$\begin{array}{l}\text { LARC uptake at } \\
\text { enrollment }(n=767)\end{array}$} & \multicolumn{2}{|c|}{$\begin{array}{l}\text { LARC uptake within } \\
\text { median } 30 \text { days }(n=193)\end{array}$} & \multirow{2}{*}{$\begin{array}{l}\text { p-value*: LARC uptake } \\
\text { at enrollment vs. } \\
\text { within } 30 \text { days }\end{array}$} & \multicolumn{2}{|c|}{$\begin{array}{l}\text { No LARC uptake } \\
(n=330) \\
\end{array}$} & \multirow[t]{2}{*}{$\begin{array}{l}p \text {-value*: Across } \\
\text { all sub-groups }\end{array}$} \\
\hline & $n$ & Column $\%$ & $n$ & Row \% & $n$ & Row \% & & $n$ & Row \% & \\
\hline Couple HIV status & & & & & & & 0.2049 & & & 0.0005 \\
\hline M-F- & 330 & $26 \%$ & 218 & $66 \%$ & 46 & $14 \%$ & & 66 & $20 \%$ & \\
\hline$M+F+$ & 327 & $25 \%$ & 198 & $61 \%$ & 54 & $17 \%$ & & 75 & $23 \%$ & \\
\hline $\mathrm{M}-\mathrm{F}+$ & 319 & $25 \%$ & 181 & $57 \%$ & 57 & $18 \%$ & & 81 & $25 \%$ & \\
\hline$M+F-$ & 314 & $24 \%$ & 170 & $54 \%$ & 36 & $11 \%$ & & 108 & $34 \%$ & \\
\hline \multicolumn{11}{|c|}{ Clinic affiliation and location } \\
\hline Urban & & & & & & & $<0.0001$ & & & $<0.0001$ \\
\hline Catholic & 315 & $24 \%$ & 148 & $47 \%$ & 66 & $21 \%$ & & 101 & $32 \%$ & \\
\hline Non-Catholic & 333 & $26 \%$ & 284 & $85 \%$ & 31 & $9 \%$ & & 18 & $5 \%$ & \\
\hline Rural & & & & & & & 0.6749 & & & $<0.0001$ \\
\hline Catholic & 317 & $25 \%$ & 142 & $45 \%$ & 43 & $14 \%$ & & 132 & $42 \%$ & \\
\hline Non-Catholic & 325 & $25 \%$ & 193 & $59 \%$ & 53 & $16 \%$ & & 79 & $24 \%$ & \\
\hline
\end{tabular}

*Chi-square test for categorical variables

HIV+ men $(71 \%)(p=0.0152)$. Concordant HIV- couples were the most likely to uptake LARC methods on the day of enrollment ( $66 \%$ vs $57 \%$ of other couples, $p=$ 0.0046). Compared to all other couples, $\mathrm{M}+\mathrm{F}$ - couples were significantly less likely to uptake LARC (66\% vs. $77 \%$ of other couples, $p=<0.0001$ ).

Uptake was higher in non-Catholic clinics $(85 \%$ vs $63 \%$ in Catholic clinics, $p<0.0001$ ), and in urban clinics (82\% vs $67 \%$ in rural clinics, $p<0.0001)$. LARC uptake was highest among urban non-Catholic clinics (95\%), followed by rural non-Catholic clinics (76\%), urban Catholic clinics (68\%), and the lowest uptake was 58\% in rural Catholic clinics $(p<0.0001)$. As expected, uptake in urban Catholic clinics was more likely to be after the date of enrollment (21\% vs $9 \%$ in urban non-Catholic clinics, $p<0.0001$ ) as it required a referral to the nearby health post which could not always be acted on the same day. Uptake at enrollment was the same in urban (47\%) and rural (45\%) Catholic clinics but lower after enrollment in rural areas $(14 \%$ vs $21 \%$ in urban Catholic clinics, $p=0.014$ ). This may reflect the greater obstacle presented by distance in rural areas.

\section{Demographic factors associated with LARC uptake after the intervention (Table 2)}

Mean ages were 31 for women and 35-36 for men, with concordant negative couples having the youngest mean ages compared to all other serostatus groups (29.3 vs. $31.0, p<0.0001$ and 33.3 vs. 37.3, $p<0.0001$, for women and men respectively). Mean duration of union was 6-7 years with concordant positive couples having the longest mean duration of cohabitation compared to all other serostatus groups (7.8 vs. $6.8, p=0.0020)$ and concordant negative couples the shortest mean duration compared to all other serostatus groups ( 6.3 vs. $7.3, p=$ 0.0009 ). The mean number of biological children was 2.2 with no significant differences between serostatus groups.

Couples who requested LARC were on average younger (35.7 vs. 37.9 for men, 30.4 vs. 31.1 for women), had lived in Kigali (16.1 vs.19.1 years for men, 13.3 vs.15.3 for women), and cohabited for fewer years (6.7 vs. 8.2 years) and had fewer children (2.2 biological and 2.7 in the home vs. 2.4 biological and 3.0 in the home for nonLARC couples). These differences were all statistically significant.

Not completing primary school was reported by $42 \%$ of women and $37 \%$ of men, with concordant HIV- couples having the highest educational achievements and concordant positive couples the lowest $(p<0.0001$ for both men and women). Literacy results were similar with $66 \%$ of men and $61 \%$ of women able to read easily in Kinyarwanda but a substantial difference between M-F- couples ( $80 \%$ of men and $76 \%$ of women read easily) and $M+F+$ couples ( $54 \%$ of men and $48 \%$ of women) $(p<0.0001$ for both men and women). Discordant couples had intermediate literacy with 58-68\% reporting easily reading Kinyarwanda. Reading easily in English or French was uncommon (2-4\% overall) with M-F- couples again having the highest literacy $(7-8 \%)$ and $\mathrm{M}+\mathrm{F}+$ couples the lowest $(1-2 \%)(p<0.0001$ for both men and women). Most (94\%) men and $43 \%$ of women reported some income with a monthly median of 40,000 Rwandan francs (\$50) for men and 20,000 Rwandan francs (\$25) for women (not shown). 
Table 2 Significant individual and couple-level demographic factors associated with LARC uptake after the intervention

\begin{tabular}{|c|c|c|c|c|c|c|c|}
\hline & \multicolumn{2}{|c|}{$\begin{array}{l}\text { All Couples } \\
(n=1290)\end{array}$} & \multicolumn{2}{|c|}{$\begin{array}{l}\text { LARC uptake at baseline or } \\
\text { within median } 30 \text { days } \\
(n=960)\end{array}$} & \multicolumn{2}{|c|}{$\begin{array}{l}\text { Did not uptake } \\
\text { LARC }(n=330)\end{array}$} & \multirow[t]{2}{*}{$p$-value* } \\
\hline & mean & SD & mean & SD & mean & SD & \\
\hline Man's Age & 36.3 & 8.2 & 35.7 & 8.2 & 37.9 & 8.2 & $<0.0001$ \\
\hline Woman's Age & 30.6 & 5.4 & 30.4 & 5.5 & 31.1 & 5.1 & 0.0240 \\
\hline Man's Years in Kigali & 16.9 & 11.8 & 16.1 & 11.6 & 19.1 & 11.9 & $<0.0001$ \\
\hline Woman's Years in Kigali & 13.8 & 10.1 & 13.3 & 10.1 & 15.3 & 10.2 & 0.0017 \\
\hline Cohabitation (years) & 7.1 & 5.0 & 6.7 & 4.9 & 8.2 & 5.1 & $<0.0001$ \\
\hline Number of biological children & 2.2 & 1.4 & 2.2 & 1.3 & 2.4 & 1.5 & 0.0190 \\
\hline \multirow[t]{2}{*}{ Number of children in household } & 2.8 & 1.6 & 2.7 & 1.5 & 3.0 & 1.6 & 0.0004 \\
\hline & $n$ & $\begin{array}{l}\text { Column } \\
\%\end{array}$ & $n$ & Row \% & $n$ & Row \% & \\
\hline Man Reads Kinyarwanda & & & & & & & 0.0144 \\
\hline Easily/with difficulty & 1005 & $78 \%$ & 732 & $73 \%$ & 273 & $27 \%$ & \\
\hline Not at all & 285 & $22 \%$ & 228 & $80 \%$ & 57 & $20 \%$ & \\
\hline Man Reads French & & & & & & & 0.0066 \\
\hline Easily/with difficulty & 198 & $15 \%$ & 132 & $67 \%$ & 66 & $33 \%$ & \\
\hline Not at all & 1092 & $85 \%$ & 828 & $76 \%$ & 264 & $24 \%$ & \\
\hline Man's Level of Education & & & & & & & 0.0004 \\
\hline Primary/Secondary/Tertiary & 813 & $63 \%$ & 578 & $71 \%$ & 235 & $29 \%$ & \\
\hline No education & 477 & $37 \%$ & 382 & $80 \%$ & 95 & $20 \%$ & \\
\hline Woman's Level of Education & & & & & & & 0.0225 \\
\hline Primary/Secondary/Tertiary & 752 & $58 \%$ & 542 & $72 \%$ & 210 & $28 \%$ & \\
\hline No education & 538 & $42 \%$ & 418 & $78 \%$ & 120 & $22 \%$ & \\
\hline Man's Religion & & & & & & & 0.0005 \\
\hline Catholic/Other & 635 & $49 \%$ & 500 & $79 \%$ & 135 & $21 \%$ & \\
\hline $\begin{array}{l}\text { Pentecostal/Seven Day Adventist/Jehovah's Witnesses/Anglican/ } \\
\text { Baptist/Muslim/No religion }\end{array}$ & 655 & $51 \%$ & 460 & $70 \%$ & 195 & $30 \%$ & \\
\hline Woman's Religion & & & & & & & 0.0019 \\
\hline Catholic/Other & 535 & $41 \%$ & 432 & $81 \%$ & 103 & $19 \%$ & \\
\hline $\begin{array}{l}\text { Pentecostal/Seven Day Adventist/Jehovah's Witnesses/Anglican/Baptist/ } \\
\text { Muslim/No religion }\end{array}$ & 755 & $59 \%$ & 528 & $70 \%$ & 227 & $30 \%$ & \\
\hline Couple Religion & & & & & & & $<0.0001$ \\
\hline Both Catholic/Other & 425 & $33 \%$ & 340 & $80 \%$ & 85 & $20 \%$ & \\
\hline $\begin{array}{l}\text { Woman Catholic/Other, Man Pentecostal/Seven Day Adventist/Jehovah's } \\
\text { Witnesses/Anglican/Baptist/Muslim/No religion }\end{array}$ & 110 & $9 \%$ & 92 & $84 \%$ & 18 & $16 \%$ & \\
\hline $\begin{array}{l}\text { Man Catholic/Other, Woman Pentecostal/Seven Day Adventist/Jehovah's } \\
\text { Witnesses/Anglican/Baptist/Muslim/No religion }\end{array}$ & 210 & $16 \%$ & 160 & $76 \%$ & 50 & $24 \%$ & \\
\hline $\begin{array}{l}\text { Both Pentecostal/Seven Day Adventist/Jehovah's Witnesses/Anglican/ } \\
\text { Baptist/Muslim/No religion }\end{array}$ & 545 & $42 \%$ & 368 & $68 \%$ & 177 & $32 \%$ & \\
\hline Man frequency of attending religious services & & & & & & & 0.0001 \\
\hline More than once a week & 272 & $21 \%$ & 178 & $65 \%$ & 94 & $35 \%$ & \\
\hline Once a week or less often & 1018 & $79 \%$ & 782 & $77 \%$ & 236 & $23 \%$ & \\
\hline Woman frequency of attending religious services & & & & & & & $<0.0001$ \\
\hline More than once a week & 392 & $30 \%$ & 262 & $67 \%$ & 130 & $33 \%$ & \\
\hline Once a week or less often & 898 & $70 \%$ & 698 & $78 \%$ & 200 & $22 \%$ & \\
\hline
\end{tabular}

Man's frequency of attending religious services by religion 
Table 2 Significant individual and couple-level demographic factors associated with LARC uptake after the intervention (Continued)

\begin{tabular}{|c|c|c|c|c|c|c|c|}
\hline & \multicolumn{2}{|c|}{$\begin{array}{l}\text { All Couples } \\
(n=1290)\end{array}$} & \multicolumn{2}{|c|}{$\begin{array}{l}\text { LARC uptake at baseline or } \\
\text { within median } 30 \text { days } \\
(n=960)\end{array}$} & \multicolumn{2}{|c|}{$\begin{array}{l}\text { Did not uptake } \\
\text { LARC }(n=330)\end{array}$} & \multirow[t]{2}{*}{$p$-value* } \\
\hline & mean & SD & mean & SD & mean & SD & \\
\hline Catholic/Other & & & & & & & 0.0578 \\
\hline More than once a week & 66 & $10 \%$ & 46 & $70 \%$ & 20 & $30 \%$ & \\
\hline Once a week or less often & 569 & $90 \%$ & 454 & $80 \%$ & 115 & $20 \%$ & \\
\hline $\begin{array}{l}\text { Pentecostal/Seven Day Adventist/Jehovah's Witnesses/Anglican/Baptist/ } \\
\text { Muslim/No religion }\end{array}$ & & & & & & & 0.0197 \\
\hline More than once a week & 206 & $31 \%$ & 132 & $64 \%$ & 74 & $36 \%$ & \\
\hline Once a week or less often & 449 & $69 \%$ & 328 & $73 \%$ & 121 & $27 \%$ & \\
\hline \multicolumn{8}{|l|}{ Woman's frequency of attending religious services by religion } \\
\hline Catholic/Other & & & & & & & 0.3745 \\
\hline More than once a week & 98 & $18 \%$ & 76 & $78 \%$ & 22 & $22 \%$ & \\
\hline Once a week or less often & 437 & $82 \%$ & 356 & $81 \%$ & 81 & $19 \%$ & \\
\hline $\begin{array}{l}\text { Pentecostal/Seven Day Adventist/Jehovah's Witnesses/Anglican/Baptist/ } \\
\text { Muslim/No religion }\end{array}$ & & & & & & & 0.0014 \\
\hline More than once a week & 294 & $39 \%$ & 186 & $63 \%$ & 108 & $37 \%$ & \\
\hline Once a week or less often & 461 & $61 \%$ & 342 & $74 \%$ & 119 & $26 \%$ & \\
\hline
\end{tabular}

*Two-tailed t-test for continuous variables and chi-square test for categorical variables

The following demographic covariates were analyzed but were not associated with LARC uptake in chi-square analysis and are not presented above: man has income; woman has income, woman's literacy in English, French, and Kinyarwanda; man's literacy in English

Table 2 presents significant individual and couple-level demographic factors associated with LARC uptake after the intervention. Variables not associated with LARC appear as footnotes to the table. Among both men and women, LARC uptake was highest in those with no education ( $80 \%$ of men and $78 \%$ of women) compared with those who had completed at minimum primary school ( $71 \%$ of men and $72 \%$ of women). Among men, literacy in Kinyarwanda and French was associated with lower LARC uptake ( $73 \%$ vs. $80 \%$ of illiterate and $67 \%$ vs. $76 \%$ of illiterate, respectively).

The most commonly reported religious affiliation among men was Catholicism ( $44 \%$ vs. $34 \%$ of women, $p<0.0001$ ), while women were more likely to report being Pentecostal (36\% vs. $23 \%$ of men, $p<0.0001)$. There were no notable differences in religious affiliation between couple HIV status groups. Other Protestant denominations included 9\% Seventh Day Adventist, 4\% Anglican, 1\% each Jehovah witnesses and Baptist, with no difference between genders. Fifteen percent of participants were not Catholic nor Protestant: this included Muslims (6\%), other (6\%) and those reporting no religious affiliation (3\%). LARC uptake was similar in all Protestant groups and in the Muslim/other/no religion categories and these are combined in Table 2.

Religion and frequency of attending religious services were associated with LARC uptake among both men and women, with Catholics $(78 \%$ of men and $80 \%$ of women) having the highest and Protestants (70\% of men and $71 \%$ of women) the lowest LARC uptake. Attending services more than once a week was also associated with lower LARC uptake $(65-67 \%$ of men and women, respectively) compared with those attending services once a week or less (77\% of men and $78 \%$ of women). Among men this trend was noted in all religious groups though with only borderline significance among Catholics. In contrast, among women, only Protestants who attended services more than once/week had lower LARC uptake than those attending only once per week or less.

\section{HIV status, fertility goals, contraceptive experiences and concerns associated with LARC uptake after the intervention (Table 3)}

As reported above, couples with HIV+ men were less likely to uptake LARC. Among HIV+ men reporting ARV use, LARC uptake was lower (69\% vs. $85 \%$ of couples with non-ARV-using HIV+ men). These associations with HIV status and ARV use were not noted for women.

Somewhat counter-intuitively, planning to have more children was associated with higher LARC uptake $(77 \%$ vs. $72 \%$ of those not planning to have more children). For men, the most common source of information about family planning was the clinic, CHW (associated with higher LARC uptake), or radio (associated with lower LARC uptake). Half of couples had previously discussed LARC together and this was associated with a $94 \%$ uptake of LARC methods compared with only $54 \%$ among 
Table 3 HIV status, fertility goals, contraceptive experiences and concerns associated with LARC uptake after the intervention

\begin{tabular}{|c|c|c|c|c|c|c|c|}
\hline & \multicolumn{2}{|c|}{$\begin{array}{l}\text { All Couples } \\
(n=1290)\end{array}$} & \multicolumn{2}{|c|}{$\begin{array}{l}\text { LARC uptake at baseline or within } \\
\text { median } 30 \text { days }(n=960)\end{array}$} & \multicolumn{2}{|c|}{$\begin{array}{l}\text { Did not uptake LARC } \\
(n=330)\end{array}$} & \multirow[t]{2}{*}{$p$-value } \\
\hline & $\mathrm{n}$ & Column \% & $\mathrm{n}$ & Row \% & $\mathrm{n}$ & Row \% & \\
\hline Man's HIV Status & & & & & & & 0.0152 \\
\hline Positive & 641 & $50 \%$ & 458 & $71 \%$ & 183 & $29 \%$ & \\
\hline Negative & 649 & $50 \%$ & 502 & $77 \%$ & 147 & $23 \%$ & \\
\hline Of HIV+, man on ARV & & & & & & & 0.0001 \\
\hline Yes & 537 & $84 \%$ & 370 & $69 \%$ & 167 & $31 \%$ & \\
\hline No & 104 & $16 \%$ & 88 & $85 \%$ & 16 & $15 \%$ & \\
\hline Plan to have more children & & & & & & & 0.0283 \\
\hline Yes/Unsure & 634 & $49 \%$ & 489 & $77 \%$ & 145 & $23 \%$ & \\
\hline No & 656 & $51 \%$ & 471 & $72 \%$ & 185 & $28 \%$ & \\
\hline Previously discussed family planning as a couple & & & & & & & $<0.0001$ \\
\hline Yes & 1201 & $93 \%$ & 913 & $76 \%$ & 288 & $24 \%$ & \\
\hline No & 89 & $7 \%$ & 47 & $53 \%$ & 42 & $47 \%$ & \\
\hline \multicolumn{8}{|l|}{ Couple previously discussed } \\
\hline IUD & 129 & $10 \%$ & 116 & $90 \%$ & 13 & $10 \%$ & $<0.0001$ \\
\hline Jadelle & 548 & $42 \%$ & 517 & $94 \%$ & 31 & $6 \%$ & $<0.0001$ \\
\hline IUD or Jadelle & 628 & $49 \%$ & 589 & $94 \%$ & 39 & $6 \%$ & $<0.0001$ \\
\hline \multicolumn{8}{|c|}{ Man: Sources of information about contraceptive methods } \\
\hline Community Health Worker & 398 & $31 \%$ & 310 & $78 \%$ & 88 & $22 \%$ & 0.0563 \\
\hline Radio & 406 & $31 \%$ & 281 & $69 \%$ & 125 & $31 \%$ & 0.0037 \\
\hline Newspaper & 36 & $3 \%$ & 19 & $53 \%$ & 17 & $47 \%$ & 0.0025 \\
\hline Current method to prevent pregnancy & & & & & & & 0.0001 \\
\hline Injectable & 322 & $25 \%$ & 221 & $69 \%$ & 101 & $31 \%$ & \\
\hline Condoms & 591 & $46 \%$ & 427 & $72 \%$ & 164 & $28 \%$ & \\
\hline OCP & 93 & $7 \%$ & 76 & $82 \%$ & 17 & $18 \%$ & \\
\hline Other/None & 284 & $22 \%$ & 236 & $83 \%$ & 48 & $17 \%$ & \\
\hline Man: Concerns about implant & & & & & & & 0.0038 \\
\hline Negative side effects & 188 & $16 \%$ & 124 & $66 \%$ & 64 & $34 \%$ & \\
\hline Bad for health & 70 & $6 \%$ & 51 & $73 \%$ & 19 & $27 \%$ & \\
\hline Doesn't work & 39 & $3 \%$ & 33 & $85 \%$ & 6 & $15 \%$ & \\
\hline Other & 14 & $1 \%$ & 6 & $43 \%$ & 8 & $57 \%$ & \\
\hline No concerns & 653 & $55 \%$ & 497 & $76 \%$ & 156 & $24 \%$ & \\
\hline Don't know & 229 & $19 \%$ & 172 & $75 \%$ & 57 & $25 \%$ & \\
\hline Woman: Concerns about implant & & & & & & & $<0.0001$ \\
\hline Negative side effects & 292 & $23 \%$ & 184 & $63 \%$ & 108 & $37 \%$ & \\
\hline Bad for health & 93 & $7 \%$ & 70 & $75 \%$ & 23 & $25 \%$ & \\
\hline Doesn't work & 59 & $5 \%$ & 44 & $75 \%$ & 15 & $25 \%$ & \\
\hline Other & 15 & $1 \%$ & 9 & $60 \%$ & 6 & $40 \%$ & \\
\hline No concerns & 638 & $50 \%$ & 506 & $79 \%$ & 132 & $21 \%$ & \\
\hline Don't know & 171 & $13 \%$ & 132 & $77 \%$ & 39 & $23 \%$ & \\
\hline Man: Concerns about IUD & & & & & & & 0.0031 \\
\hline Negative side effects & 74 & $11 \%$ & 54 & $73 \%$ & 20 & $27 \%$ & \\
\hline Bad for health & 49 & $7 \%$ & 45 & $92 \%$ & 4 & $8 \%$ & \\
\hline
\end{tabular}


Table 3 HIV status, fertility goals, contraceptive experiences and concerns associated with LARC uptake after the intervention (Continued)

\begin{tabular}{|c|c|c|c|c|c|c|c|}
\hline & \multicolumn{2}{|c|}{$\begin{array}{l}\text { All Couples } \\
(n=1290)\end{array}$} & \multicolumn{2}{|c|}{$\begin{array}{l}\text { LARC uptake at baseline or within } \\
\text { median } 30 \text { days }(n=960)\end{array}$} & \multicolumn{2}{|c|}{$\begin{array}{l}\text { Did not uptake LARC } \\
(n=330)\end{array}$} & \multirow[t]{2}{*}{$p$-value* } \\
\hline & $\mathrm{n}$ & Column $\%$ & $\bar{n}$ & Row \% & $\mathrm{n}$ & Row \% & \\
\hline Doesn't work & 45 & $6 \%$ & 42 & $93 \%$ & 3 & $7 \%$ & \\
\hline Other & 12 & $2 \%$ & 8 & $67 \%$ & 4 & $33 \%$ & \\
\hline No concerns & 317 & $45 \%$ & 228 & $72 \%$ & 89 & $28 \%$ & \\
\hline Don't know & 200 & $29 \%$ & 151 & $76 \%$ & 49 & $25 \%$ & \\
\hline Woman: Concerns about IUD & & & & & & & 0.0665 \\
\hline Negative side effects & 166 & $15 \%$ & 109 & $66 \%$ & 57 & $34 \%$ & \\
\hline Bad for health & 132 & $12 \%$ & 98 & $74 \%$ & 34 & $26 \%$ & \\
\hline Doesn't work & 102 & $9 \%$ & 80 & $78 \%$ & 22 & $22 \%$ & \\
\hline Other & 39 & $4 \%$ & 29 & $74 \%$ & 10 & $26 \%$ & \\
\hline No concerns & 419 & $38 \%$ & 309 & $74 \%$ & 110 & $26 \%$ & \\
\hline Don't know & 235 & $22 \%$ & 186 & $79 \%$ & 49 & $21 \%$ & \\
\hline
\end{tabular}

*Two-tailed t-test for continuous variables and chi-square test for categorical variables

The following covariates were analyzed but were not associated with LARC uptake in chi-square analysis and are not presented above: woman's HIV or ARV status; individual or couple RPR status; preferred timing of last pregnancy; man wants more children (yes/don't know vs no); woman wants more children (yes/don't know vs no); all women's sources of information about contraceptive methods; clinic staff, friends, spouse, TV or other as men's sources of information about contraceptive methods; man previously heard of implant; woman previously heard of implant; man previously heard of IUD; woman previously heard of IUD; woman previously used implant; and woman previously used IUD

Man and woman's concerns about negative side effects from the implant and IUD were included in bivariate and multivariate models as dichotmous variables (concerned about negative side effects yes/no)

couples who had not discussed IUD or implant previously. Current use of injectable contraception or condoms as the only contraception prior to the intervention was associated with lower uptake of LARC methods $(69$ and $72 \%$, respectively compared with $82-83 \%$ of OCP and non-modern method users). Among the $92 \%$ of men and $98 \%$ of women who had previously heard of the implant, $16 \%$ of men and $23 \%$ of women thought they had negative side effects and this was associated with lower LARC uptake $(66 \%$ of men and $63 \%$ of women compared with $76 \%$ of men and $78 \%$ of women not citing negative side effects as a concern, respectively).

\section{Multivariate analysis of factors associated with LARC uptake (Table 4)}

Variables associated with LARC uptake in bivariate analysis were included in the multivariate model with the exception of man's ARV use which was collinear with man's HIV status. Interaction terms between rural/urban and Catholic/non-Catholic clinics showed non-Catholic clinics having higher uptake in both urban and rural areas and urban having higher uptake than rural in this group. In this model, the interaction term for urban vs. rural LARC uptake in Catholic clinics was not significant. Couple HIV status did not remain associated with LARC uptake in the multivariate model. Only the age of the man remained significant when both men's and women's ages and number of children were included in the model. Not having completed at least primary school remained predictive of LARC uptake among both men and women. When religious affiliation of the man and woman were combined, couples with the woman or both partners Catholic remained significantly more likely to choose a LARC method. Frequency of attending religious services did not remain independently predictive in the final multivariate model. Baseline injectable and condom use remained predictive of lower LARC uptake compared with OCP use or use of traditional or no contraception. The strongest predictor of LARC uptake was the couple having discussed one or both LARC methods prior to the day of enrollment. Higher LARC uptake was also associated with women not having concerns about implant negative side effects.

\section{Discussion}

Our intervention used a coordinated, multifaceted approach to HIV-FP integration building on the literature and prior experience in Rwanda. Key components were: including both cohabiting partners, triaging participants based on fertility goals, providing low cost group education by CHW, cross-training FP and HIV clinic staff in client-centered approaches and dual-method counseling for HIV discordant couples, training FP nurses to comfortably insert LARC methods, procurement of LARC supplies, point-of-care LARC insertion, and protected government clinic staff time. Our results confirm that when integrated with joint HIV counseling and testing, a simple intervention offering LARC to couples who desire 
Table 4 Multivariate analysis of clinic, couple and individual-level factors associated with LARC uptake after the intervention

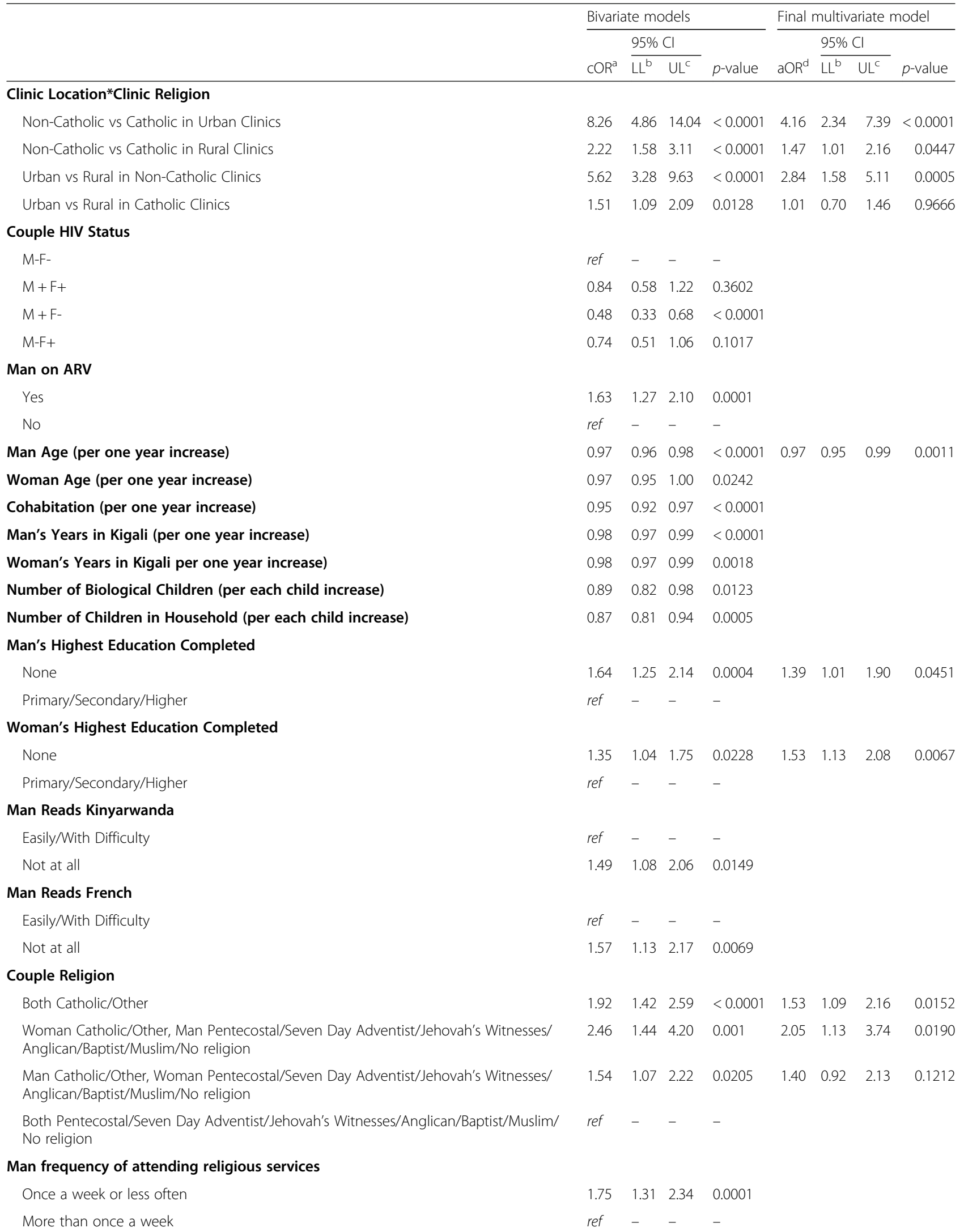


Table 4 Multivariate analysis of clinic, couple and individual-level factors associated with LARC uptake after the intervention (Continued)

\begin{tabular}{|c|c|c|c|c|c|c|c|c|}
\hline & Bivaria & ate mo & dels & & Final & multiv & ariate $n$ & nodel \\
\hline & & $95 \%$ & & & & $95 \%$ & & \\
\hline & $\mathrm{COR}^{\mathrm{a}}$ & $\mathrm{LL}^{\mathrm{b}}$ & $U L^{c}$ & $p$-value & $a O R^{d}$ & $\mathrm{LL}^{\mathrm{b}}$ & $U L^{c}$ & $p$-value \\
\hline Woman frequency of atten & & & & & & & & \\
\hline Once a week or less often & 1.73 & 1.33 & 2.52 & $<0.0001$ & & & & \\
\hline More than once a week & ref & - & - & - & & & & \\
\hline Plan to have more children & & & & & & & & \\
\hline Yes/unsure & 1.33 & 1.03 & 1.7 & 0.0285 & & & & \\
\hline No & ref & - & - & - & & & & \\
\hline Contraceptive on day of en & & & & & & & & \\
\hline Injectable & 0.45 & 0.3 & 0.66 & $<0.0001$ & 0.55 & 0.35 & 0.87 & 0.0096 \\
\hline Condoms & 0.53 & 0.37 & 0.76 & 0.0005 & 0.59 & 0.39 & 0.89 & 0.0113 \\
\hline OCP & 0.91 & 0.49 & 1.67 & 0.7601 & 1.21 & 0.61 & 2.40 & 0.5935 \\
\hline Other/None & ref & - & - & - & & & & \\
\hline Couple previously discusse & & & & & & & & \\
\hline Yes & 11.85 & 8.28 & 16.95 & $<0.0001$ & 7.59 & 5.18 & 11.13 & $<0.0001$ \\
\hline No & ref & - & - & - & & & & \\
\hline Man heard of implant and & & & & & & & & \\
\hline No & 1.62 & 1.16 & 2.26 & 0.0042 & & & & \\
\hline Yes & ref & - & - & - & & & & \\
\hline Woman heard of implant a & & & & & & & & \\
\hline No & 2.05 & 1.55 & 2.72 & $<0.0001$ & 1.49 & 1.07 & 2.07 & 0.0193 \\
\hline Yes & ref & - & - & - & & & & \\
\hline Woman heard of IUD and $c$ & & & & & & & & \\
\hline No & 1.63 & 1.15 & 2.31 & 0.0059 & & & & \\
\hline Yes & ref & - & - & - & & & & \\
\hline
\end{tabular}

The following variables were not significant in bivariate analyses and are not tabled: woman HIV+ or on ARV, man wants more children, woman wants more children, woman previously used IUD, woman previously used implant, preferred timing of last pregnancy, man concerned about negative side effects of IUD ${ }^{a}$ Crude odds ratio

b Lower limit for $95 \%$ confidence interval (CI)

'Upper limit for $95 \%$ confidence interval (Cl)

${ }^{\mathrm{d}}$ Adjusted odds ratio

to delay or limit pregnancy results in a high uptake of these methods. Overall uptake was encouraging ranging from $58 \%$ in rural Catholic clinics to $95 \%$ in urban, nonCatholic clinics. Residual obstacles at the facility- and client-level are addressable, as discussed below.

The literature on HIV-FP integration at the facilitylevel highlights the importance of structural aspects of service delivery including commodities and reagent stocks, provider knowledge and skills, workload and job satisfaction $[42,43]$. In Tanzania significant determinants of facility readiness for integrating $\mathrm{FP}$ and HIV were being government owned, having routine management meetings, availability of guidelines inservice training of staff and availability of laboratories for HIV testing [37]. In Kenya, facilities where staff were supported by management to work as a team to share workload delivered better integrated services despite resource shortages. In contrast, where staff were poorly organized and unsupported, services were poor despite structural integration [40]. A South African group developed a model for KwaZulu-Natal that provided capacity building and commodity monitoring with involvement of community members [41], while a quality improvement program for maternal, child and HIV care in South African primary health care facilities resulted in improved child services but no impact on HIV-FP integration [39]. A comparison of FP services in integrated and non-integrated clinics in Malawi and Tanzania found no adverse outcomes due to strain on facility or providers but noted strengthened FP commodity stocks likely due to HIV-related supply chains in integrated clinics [38]. An 
organizational network analysis in Ethiopia [44] led to an intervention that resulted in a $55 \%$ increase in HIV-FP referrals [45].

These experiences make clear the critical role facility and staff components play in the success of any HIV-FP program. Our intervention included capacity building and ensured that the necessary commodities were present. Hiring successful trainees when they were off duty provided a financial incentive and allowed staff to become confident and proud of their newly acquired skills. While some would argue that this approach is not sustainable, we found during the nationwide expansion of CVCT that new skills transition into day to day practice and - when supported by $\mathrm{MoH}$ mandates - eventually become the standard of care [59]. We also implemented our integrated HIV-FP model in 55 urban and 215 rural government clinics across 33 districts in Zambia: the program provided HIV-FP counseling to 208,211 couples and performed 101,322 LARC insertions [69].

Though promising, our results do expose facility level obstacles to HIV-FP integration in Rwanda, specifically the influence of Catholic affiliation and rural location. Prior to the Genocide of the Tutsi in 1994, Rwanda was predominantly Catholic [70]. Since the Genocide, the demography of religion in Rwanda has changed with a marked increase in the number of Protestants denominations, in particular Pentecostal churches [71] which were particularly popular among women in our sample. Clinics affiliated with the Catholic Church do not provide contraception but they do refer interested clients to a nearby health post established by the $\mathrm{MoH}$ for family planning [72]. Staff are provided by the $\mathrm{MoH}$ without regard to their religion and rotated regularly, therefore we presume that provider bias did not operate differentially in Catholic and non-Catholic clinics. Interestingly, the proportion of Catholic clients did not differ in Catholic and non-Catholic clinics, and Catholic women and couples were more receptive to LARC than others as has been reported by others [73, 74]. The uptake of LARC among our study participants referred from Catholic clinics to health posts, though low relative to non-Catholic clinics, was still substantial. The lower uptake in Catholic clinics was thus most likely due to the need to travel to the nearby health post rather than to any effect of personal religious beliefs.

At the client-level, time and distance were likely contributors to lower uptake in rural compared with urban clinics. Shifting the task of LARC endorsement to $\mathrm{CHW}$ is one solution to distance and physically separated services. In a related study in 8 different catchment areas in Kigali, we used the same training procedures for $\mathrm{CHW}$ as was used here, but tasked them with educating the households they were assigned to about LARC and providing written referrals for interested women and couples. Specifically, the clients they provided OCP and DMPA injections to, along with women who were post-partum or multigravida, were prioritized as target audiences that might benefit from learning about LARC [68]. In a 13 month period, CHW distributed 7712 referrals, $79 \%$ leading to clinic visits and $95 \%$ of those resulting in LARC uptake. Of note, CHW could advise interested women to go directly to the health post (rather than the Catholic clinic), and could emphasize that while traveling for LARC insertion might be burdensome, one visit resulting in long acting protection was preferable to repeated visits or a method failure.

LARC-focused content of the education sessions, targeted messaging and the focus on couples rather than women alone would not have succeeded without the structural underpinning. That said, we did identify individual and couple-level characteristics of associated with LARC uptake and indicative of gaps that should be examined.

The strongest predictor of LARC uptake was having previously discussed LARC methods as a couple, which reinforces the need to expand demand creation strategies while bolstering clinic capacity to provide LARC methods. However, concern about the negative side effects of hormonal implants remained a deterrent to LARC uptake among women. Overcoming misconceptions and knowledge gaps among providers and patients is an important and ongoing need that should be addressed by CHW and clinic staff [75].

Concordant couples were more likely to uptake LARC than discordant couples, the latter being more likely to report condom use as their only contraceptive method. Couple HIV status was likely confounded with condom use and only the latter remained predictive in the multivariate analysis. Use of DMPA as contraception was also independently associated with not choosing LARC. It may be that condom and DMPA users were satisfied with their current method and did not feel the need to have additional protection against unplanned pregnancy. However, condoms have a higher contraceptive failure rate than other modern methods, even among discordant couples who are highly motivated to adhere with them consistently [76-78], and previous studies have reported more unprotected sex in DMPA vs nonhormonal method users [79]. More impactful dualmethod counseling for condom and DMPA users may be an important improvement. Additionally, previous studies have noted high rates of discontinuation among DMPA users [80] and further study is needed to assess 
whether a LARC method might be an acceptable alternative to this subgroup.

The limitations of our study included limited generalizability of our findings given convenience sampling of couples expressing a desire to delay or limit pregnancy, limited sample size to explore some association, and loss to follow-up that may be differential by exposures of interest.

\section{Conclusions}

A combination of couples-focused education about LARC based on stated fertility goals and access to point of care LARC insertion was highly impactful in Kigali, Rwanda. Combining this program with joint HIV testing and counseling mutually leverages heterosexual and perinatal HIV prevention and unplanned pregnancy prevention. We encourage further research, both behavioral and operational, to further optimize and integrate HIV and unplanned pregnancy prevention in resource-limited settings.

\author{
Abbreviations \\ aOR: Adjusted odds ratio; CFPC: Couples' family planning counseling; \\ CHW: Community health worker; CVCT: Couples' voluntary HIV counseling \\ and testing; IUD: Intrauterine device; LARC: Long-acting reversible \\ contraception; MoH: Ministry of Health; OCP: Oral contraceptive pills; \\ PSF: Projet San Francisco; RZHRG: Rwanda Zambia HIV Research Group
}

\section{Acknowledgments}

We thank the Ministry of Health, staff and study participants from government health clinics in Kigali, Rwanda, and students and staff of Emory, PSF and RZHRG.

\section{Authors' contributions}

JM made substantial contributions to conception and design, acquisition of data, and analysis and interpretation of data. RI, JN, AA, GA, SRE, AT, NK, SA EK made substantial contributions to conception, design, and analysis and interpretation of data. RP and KMW made substantial contributions to analysis and interpretation of data. All authors have been involved in drafting the manuscript or revising it critically for important intellectual content, have given final approval of the version to be published, and agree to be accountable for all aspects of the work in ensuring that questions related to the accuracy or integrity of any part of the work are appropriately investigated and resolved.

\section{Funding}

The authors have no conflicts of interest to declare. This work was supported by National Institutes of Health (https://www.nih.gov/) grants [R01 MH66767, R01 HD40125, and R01 MH95503; K01 MH107320, R01 Al051231]; the AIDS International Training and Research Program Fogarty International Center [D43 TW001042]; and the Emory Center for AIDS Research [P30 Al050409]. Additional support was provided by the International AIDS Vaccine Initiative (https://www.iavi.org/). This work was also supported through the SubSaharan African Network for TB/HIV Research Excellence (SANTHE), a DELTAS Africa Initiative [grant \# DEL-15-006]. The DELTAS Africa Initiative is an independent funding scheme of the African Academy of Sciences (AAS)'s Alliance for Accelerating Excellence in Science in Africa (EASA) and supported by the New Partnership for Africa's Development Planning and Coordinating Agency (NEPAD Agency) with funding from Wellcome Trust [grant \# 107752/ $Z / 15 / Z]$ and the UK government. The views expressed in this publication are those of the author(s) and not necessarily of those for AAS, NEPAD Agency, Wellcome Trust or the UK government'. The contents are the responsibility of the authors and do not necessarily reflect the views of sponsors, who had no role in study design, data collection and analysis, decision to publish, or preparation of the manuscript. The corresponding author had full access to all the data in the study and had final responsibility for the decision to submit for publication.

\section{Availability of data and materials}

The datasets used and/or analyzed during the current study are available from the corresponding author on reasonable request.

\section{Ethics approval and consent to participate}

Participants signed joint written informed consent approved by IRBS registered with the Health and Human Services Office of Human Research Protection (Emory University IRBs 453 and 569, Rwanda Ministry of Health IRB 1497).

\section{Consent for publication}

Not applicable.

\section{Competing interests}

The authors declare that they have no competing interests.

\section{Author details}

${ }^{1}$ Projet San Francisco, Rwanda Zambia HIV Research Group, Kigali, Rwanda. ${ }^{2}$ Rwanda Zambia HIV Research Group, Department of Pathology \& Laboratory Medicine, School of Medicine, Emory University, Atlanta, GA, USA. ${ }^{3}$ London School of Hygiene \& Tropical Medicine (LSHTM), Keppel Street, London WC1E 7HT, UK. ${ }^{4}$ Medical Research Council, Uganda Vaccine Research Institute \& LSHTM Uganda Research Unit, Entebbe, Uganda. ${ }^{5}$ Department of Obstetrics, Gynecology and Reproductive Biology, Brigham and Women's Hospital, Harvard Medical School, Boston, MA, USA. ${ }^{6}$ Department of Epidemiology, Rollins School of Public Health, Emory University, Atlanta, GA, USA. ${ }^{7}$ University of Rwanda School of Public Health, Kigali, Rwanda. ${ }^{8}$ Department of Psychiatry and Behavioral Sciences, School of Medicine, Emory University, Atlanta, GA, USA. ${ }^{9}$ International AIDS Vaccine Initiative, New York, NY, USA. ${ }^{10}$ Department of Epidemiology and Biostatistics, University of California at San Francisco, San Francisco, CA, USA

Received: 10 June 2019 Accepted: 11 August 2020

Published online: 17 August 2020

\section{References}

1. Trussell J, Lalla AM, Doan QV, Reyes E, Pinto L, Gricar J. Cost effectiveness of contraceptives in the United States. Contraception. 2009;79(1):5-14.

2. Trussell J. Contraceptive failure in the United States. Contraception. 2004; 70(2):89-96.

3. Trussell J, Vaughan B. Contraceptive failure, method-related discontinuation and resumption of use: results from the 1995 National Survey of family growth. Fam Plan Perspect. 1999;31(2):64-72 93.

4. Hatcher RTJ, Stewart F, Stewart G, Kowall D, Guest F, Cates W, Policar M. Contraceptive technology. New York: Irvington Publishers, Inc.; 1994.

5. Steiner MJ, Lopez LM, Grimes DA, Cheng L, Shelton J, Trussell J, et al. Sinoimplant (II)--a levonorgestrel-releasing two-rod implant: systematic review of the randomized controlled trials. Contraception. 2010;81(3):197-201.

6. Khu NH, Vwalika B, Karita E, Kilembe W, Bayingana RA, Sitrin D, et al. Fertility goal-based counseling increases contraceptive implant and IUD use in HIVdiscordant couples in Rwanda and Zambia. Contraception. 2013;88(1):74-82.

7. Grabbe K, Stephenson R, Vwalika B, Ahmed Y, Vwalika C, Chomba E, et al. Knowledge, use, and concerns about contraceptive methods among serodiscordant couples in Rwanda and Zambia. J Women's Health (Larchmt). 2009;18(9):1449-56.

8. Stephenson R, Grabbe K, Vwalika B, Ahmed Y, Vwalika C, Haworth A, et al. The influence of informed consent content on study Participants' contraceptive knowledge and concerns. Stud Fam Plan. 2010;41(3):217-24.

9. Mmeje O, Njoroge B, Akama E, Leddy A, Breitnauer B, Darbes L, et al. Perspectives of healthcare providers and HIV-affected individuals and couples during the development of a safer conception counseling toolkit in Kenya: stigma, fears, and recommendations for the delivery of services. AIDS Care. 2016;28(6):750-7.

10. Gaffikin L, Phiri A, McGrath J, Zinanga A, Blumenthal PD. Provider attitudes toward IUD provision in Zimbabwe: perception of HIV risk and training implications. Adv Contracept. 1998;14(1):27-39.

11. Milford C, Greener LR, Beksinska M, Greener R, Mabude Z, Smit J. Provider understandings of and attitudes towards integration: implementing an HIV and sexual and reproductive health service integration model, South Africa. Afr J AIDS Res. 2018;17(2):183-92. 
12. Tao AR, Onono M, Baum S, Grossman D, Steinfeld R, Cohen CR, et al. Providers' perspectives on male involvement in family planning in the context of a cluster-randomized controlled trial evaluating integrating family planning into HIV care in Nyanza Province, Kenya. AIDS Care. 2015; 27(1):31-7.

13. Kakaire O, Tumwesigye NM, Byamugisha JK, Gemzell-Danielsson K. Acceptability of intrauterine contraception among women living with human immunodeficiency virus: a randomised clinical trial. Eur J Contracept Reprod Health Care. 2016;21(3):220-6.

14. Aizire J, Dadabhai S, Taulo F, Makanani B, Gadama L, Sun J, et al. Use of effective family planning methods and frequency of sex among HIV-infected and HIV-uninfected African women. Contracept Reprod Med. 2018;3:10.

15. Damian DJ, George JM, Martin E, Temba B, Msuya SE. Prevalence and factors influencing modern contraceptive use among HIV-positive women in Kilimanjaro region, northern Tanzania. Contracept Reprod Med. 2018;3:7

16. Breitnauer BT, Mmeje O, Njoroge B, Darbes LA, Leddy A, Brown J. Community perceptions of childbearing and use of safer conception strategies among HIV-discordant couples in Kisumu, Kenya. J Int AIDS Soc. 2015;18:19972.

17. Brown J, Njoroge B, Akama E, Breitnauer B, Leddy A, Darbes L, et al. A novel safer conception counseling toolkit for the prevention of HIV: a mixedmethods evaluation in Kisumu, Kenya. AIDS Educ Prev. 2016;28(6):524-38.

18. Rodriguez VJ, Cook RR, Weiss SM, Peltzer K, Jones DL. Psychosocial correlates of patient-provider family planning discussions among HIVinfected pregnant women in South Africa. Open Access J Contracept. 2017; 8:25-33.

19. Hatcher AM, Darbes L, Kwena Z, Musoke PL, Rogers AJ, Owino G, et al. Pathways for HIV prevention behaviors following a home-based couples intervention for pregnant women and male Partners in Kenya. AIDS Behav. 2020;24(7):2091-100

20. Homsy J, King R, Bannink F, Namukwaya Z, Vittinghof E, Amone A, et al. Primary HIV prevention in pregnant and lactating Ugandan women: a randomized trial. PLoS One. 2019;14(2):e0212119.

21. Schwartlander B, Stover J, Hallett T, Atun R, Avila C, Gouws E, et al. Towards an improved investment approach for an effective response to HIV/AIDS. Lancet. 2011;377(9782):2031-41.

22. Peterman TA, Todd KA, Mupanduki I. Opportunities for targeting publicly funded human immunodeficiency virus counseling and testing. J Acquir Immune Defic Syndr Hum Retrovirol. 1996;12(1):69-74.

23. Sweeney C. 1 of 3 pregnancies unwanted. Popline. 1992;14:1.

24. McCarthy GA, Cockell AP, Kell PD, Beevor AS, Boag FC. A women-only clinic for HIV, genitourinary medicine and substance misuse. Genitourin Med. 1992;68(6):386-9.

25. Carlin EM, Russell JM, Sibley K, Boag FC. Evaluating a designated family planning clinic within a genitourinary medicine clinic [see comments]. Genitourin Med. 1995;71(2):106-8.

26. Adeniyi OV, Ajayi Al, Moyaki MG, Goon DT, Avramovic G, Lambert J. High rate of unplanned pregnancy in the context of integrated family planning and HIV care services in South Africa. BMC Health Serv Res. 2018;18(1):140.

27. Chen Y, Begnel E, Muthigani W, Achwoka D, McGrath CJ, Singa B, et al. Higher contraceptive uptake in HIV treatment centers offering integrated family planning services: a national survey in Kenya. Contraception. 2020; 102(1):39-45.

28. Cohen CR, Grossman D, Onono M, Blat C, Newmann SJ, Burger RL, et al. Integration of family planning services into HIV care clinics: results one year after a cluster randomized controlled trial in Kenya. PLoS One. 2017;12(3):e0172992.

29. Mantell JE, Cooper D, Exner TM, Moodley J, Hoffman S, Myer L, et al. Emtonjeni-a structural intervention to integrate sexual and reproductive health into public sector HIV Care in Cape Town, South Africa: results of a phase II study. AIDS Behav. 2017;21(3):905-22.

30. Onono M, Guze MA, Grossman D, Steinfeld R, Bukusi EA, Shade $S$, et al. Integrating family planning and HIV services in western Kenya: the impact on HIV-infected patients' knowledge of family planning and male attitudes toward family planning. AIDS Care. 2015;27(6):743-52.

31. Brunie A, Mucheri PNW, Akol A, Chen M, Mercer SJ, Petruney T. Integrating family planning and HIV Services at the Community Level: formative assessment with village health teams in Uganda. Afr J Reprod Health. 2017; 21(2):73-80.

32. Church K, Warren CE, Birdthistle I, Ploubidis GB, Tomlin K, Zhou W, et al. Impact of integrated services on HIV testing: a nonrandomized trial among Kenyan family planning clients. Stud Fam Plan. 2017:48(2):201-18.
33. Narasimhan M, Yeh PT, Haberlen S, Warren CE, Kennedy CE. Integration of HIV testing services into family planning services: a systematic review. Reprod Health. 2019;16(Suppl 1):61.

34. Cates W Jr, Stone K. Family planning, sexually transmitted disease, and contraceptive choice: a literature update part II. Fam Plan Perspect. 1992; 24(3):122-8.

35. Daley D. Reproductive health and AIDS-related services for women: how well are they integrated? Fam Plan Perspect. 1994;26(6):264-9.

36. Stein Z. Family planning, sexually transmitted diseases, and the prevention of AIDS--divided we fail? Am J Public Health. 1996:86(6):783-4.

37. Bintabara D, Nakamura K, Seino K. Determinants of facility readiness for integration of family planning with HIV testing and counseling services: evidence from the Tanzania service provision assessment survey, 2014-2015. BMC Health Serv Res. 2017;17(1):844.

38. Close MA, Barden-O'Fallon J, Mejia C. Quality of family planning services in HIV integrated and non-integrated health facilities in Malawi and Tanzania. Reprod Health. 2019;16(Suppl 1):58.

39. Haskins L, Chiliza J, Barker P, Connolly C, Phakathi S, Feeley A, et al. Evaluation of the effectiveness of a quality improvement intervention to support integration of maternal, child and HIV care in primary health care facilities in South Africa. BMC Public Health. 2020;20(1):318.

40. Mayhew SH, Sweeney S, Warren CE, Collumbien M, Ndwiga C, Mutemwa R, et al. Numbers, systems, people: how interactions influence integration. Insights from case studies of HIV and reproductive health services delivery in Kenya. Health Policy Plan. 2017;32(suppl_4):iv67-81.

41. Milford C, Scorgie F, Rambally Greener L, Mabude Z, Beksinska M, Harrison $A$, et al. Developing a model for integrating sexual and reproductive health services with HIV prevention and care in KwaZulu-Natal, South Africa. Reprod Health. 2018;15(1):189.

42. Mutemwa R, Mayhew SH, Warren CE, Abuya T, Ndwiga C, Kivunaga J. Does service integration improve technical quality of care in low-resource settings? An evaluation of a model integrating HIV care into family planning services in Kenya. Health Policy Plan. 2017;32(suppl_4):iv91-iv101.

43. Mutisya R, Wambua J, Nyachae P, Kamau M, Karnad SR, Kabue M. Strengthening integration of family planning with HIV/AIDS and other services: experience from three Kenyan cities. Reprod Health. 2019;16(Suppl 1):62

44. Thomas JC, Reynolds H, Bevc C, Tsegaye A. Integration opportunities for HIV and family planning services in Addis Ababa, Ethiopia: an organizational network analysis. BMC Health Serv Res. 2014;14:22.

45. Thomas JC, Reynolds HW, Alterescu X, Bevc C, Tsegaye A. Improving referrals and integrating family planning and HIV services through organizational network strengthening. Health Policy Plan. 2016;31(3):302-8.

46. Ingabire R, Mukamuyango J, Nyombayire J, Easter SR, Parker R, Mazzei A, et al. Development and uptake of long-acting reversible contraception Services in Rwanda, 2009-2016. J Women's Health (Larchmt). 2019;28(12): 1640-9.

47. Hageman KM, Karita E, Kayitenkore K, Bayingana R, van der Straten A, Stephenson R, et al. What the better half is thinking: a comparison of men's and women's responses and agreement between spouses regarding reported sexual and reproductive behaviors in Rwanda. Psychol Res Behav Manag. 2009;2:47-58.

48. Schwandt HM, Feinberg S, Akotiah A, Douville TY, Gardner EV, Imbabazi C, et al. "family planning in Rwanda is not seen as population control, but rather as a way to empower the people": examining Rwanda's success in family planning from the perspective of public and private stakeholders. Contracept Reprod Med. 2018;3:18

49. Basinga P, Moore AM, Singh SD, Carlin EE, Birungi F, Ngabo F. Abortion incidence and postabortion care in Rwanda. Stud Fam Plan. 2012;43(1):1120.

50. Wall KM, Bayingana $R$, Ingabire $R$, Ahlschlager $L$, Tichacek A, Allen $S$, et al. Rwandan stakeholder perspectives of integrated family planning and HIV services. Int J Health Plann Manag. 2018;33(4):e1037-e49.

51. Cooper D, Mantell JE, Moodley J, Mall S. The HIV epidemic and sexual and reproductive health policy integration: views of south African policymakers. BMC Public Health. 2015;15:217.

52. McGinn EK, Irani L. Provider-initiated family planning within HIV Services in Malawi: did policy make it into practice? Glob Health Sci Pract. 2019;7(4): 540-50.

53. Mutalemwa PP, Kisinza WN, Munga M, Urassa JA, Kibona S, Mwingira U, et al. Integrating reproductive and child health and HIV services in Tanzania: 
implication to policy, systems and services. Tanzan J Health Res. 2013;15(2): 143-51.

54. Haddad LB, Wall KM, Kilembe W, Vwalika B, Khu NH, Brill I, et al. Bacterial vaginosis modifies the association between hormonal contraception and HIV acquisition. AIDS. 2018;32(5):595-604.

55. Ndaruhuye DM, Broekhuis A, Hooimeijer P. Demand and unmet need for means of family limitation in Rwanda. Int Perspect Sex Reprod Health. 2009; 35(3):122-30.

56. Binagwaho A, Kankindi I, Kayirangwa E, Nyemazi JP, Nsanzimana S, Morales F, et al. Transitioning to country ownership of HIV programs in Rwanda. PLoS Med. 2016;13(8):e1002075.

57. Dunkle KL, Stephenson R, Karita E, Chomba E, Kayitenkore K, Vwalika C, et al. New heterosexually transmitted HIV infections in married or cohabiting couples in urban Zambia and Rwanda: an analysis of survey and clinical data. Lancet. 2008;371(9631):2183-91.

58. Dunkle KL, Greenberg L, Lanterman A, Stephenson R, Allen S. Source of new infections in generalised HIV epidemics -- Authors' reply. Lancet. 2008; 372(9646):1300-1.

59. Karita E, Nsanzimana S, Ndagije F, Wall KM, Mukamuyango J, Mugwaneza P. et al. Implementation and operational research: evolution of Couples' voluntary counseling and testing for HIV in Rwanda: from research to public health practice. J Acquir Immune Defic Syndr. 2016;73(3):e51-e8.

60. Binagwaho A, Ratnayake N, Mukherjee J, Mugabo J, Karita E, Pegurri E. When one can infect two: a reflection on the impact of HIV discordance on child HIV infection. Pan Afr Med J. 2010:5:10.

61. Reynolds HW, Janowitz B, Wilcher R, Cates W. Contraception to prevent HIVpositive births: current contribution and potential cost savings in PEPFAR countries. Sex Transm Infect. 2008;84(Suppl 2):ii49-53.

62. Nakakeeto ON, Umaranayake L. The global strategy to eliminate HIV infection in infants and young children: a seven-country assessment of costs and feasibility. AIDS. 2009;23(8):987-95.

63. Petruney T, Harlan SV, Lanham M, Robinson ET. Increasing support for contraception as HIV prevention: stakeholder mapping to identify influential individuals and their perceptions. PLoS One. 2010;5(5):e10781.

64. Leslie JA, Munyambanza E, Adamchak SE, Janowitz B, Grey TW, Kirota K. Without strong integration of family planning into PMTCT services in Rwanda, clients remain with a high unmet need for effective family planning. Afr J Reprod Health. 2010;14(4 Spec no.):144-6.

65. Thiese MS. Observational and interventional study design types; an overview. Biochem med (Zagreb). 2014;24(2):199-210.

66. Boeras DI, Luisi N, Karita E, McKinney S, Sharkey T, Keeling M, et al. Indeterminate and discrepant rapid HIV test results in couples' HIV testing and counselling centres in Africa. J Int AIDS Soc. 2011;14:18.

67. Dionne-Odom J, Karita E, Kilembe W, Henderson F, Vwalika B, Bayingana R, et al. Syphilis treatment response among HIV-discordant couples in Zambia and Rwanda. Clin Infect Dis. 2013;56(12):1829-37.

68. Mazzei A, Ingabire R, Mukamuyango J, Nyombayire J, Sinabamenye R, Bayingana R, et al. Community health worker promotions increase uptake of long-acting reversible contraception in Rwanda. Reprod Health. 2019;16(1):75.

69. Malama K, Kilembe W, Inambao M, Hoagland A, Sharkey T, Parker R, et al. A couple-focused, integrated unplanned pregnancy and HIV prevention program in urban and rural Zambia. Am J Obstet Gynecol. 2020;222(4S): S915 e1-S e10.

70. Allen S, Lindan C, Serufilira A, Van de Perre P, Rundle AC, Nsengumuremyi F, et al. Human immunodeficiency virus infection in urban Rwanda. Demographic and behavioral correlates in a representative sample of childbearing women. JAMA. 1991;266(12):1657-63.

71. Stephenson R, Barker J, Cramer R, Hall MA, Karita E, Chomba E, et al. The demographic profile of sero-discordant couples enrolled in clinical research in Rwanda and Zambia. AIDS Care. 2008;20(3):395-405.

72. May JF, Mukamanzi M, Vekemans M. Family planning in Rwanda: status and prospects. Stud Fam Plan. 1990;21(1):20-32.

73. Schenker JG, Rabenou V. Family planning: cultural and religious perspectives. Hum Reprod. 1993;8(6):969-76.

74. Schenker JG, Rabenou V. Contraception: traditional and religious attitudes. Eur J Obstet Gynecol Reprod Biol. 1993;49(1-2):15-8.

75. Wall KM, Kilembe W, Vwalika B, Ravindhran P, Khu NH, Brill I, et al. Hormonal contraceptive use among HIV-positive women and HIV transmission risk to male partners, Zambia, 1994-2012. J Infect Dis. 2016;214(7):1063-71.

76. Wall KM, Haddad L, Vwalika B, Htee Khu N, Brill I, Kilembe W, et al. Unintended pregnancy among HIV positive couples receiving integrated
HIV counseling, testing, and family planning services in Zambia. PLoS One. 2013:8(9):e75353.

77. Wall KM, Kilembe W, Vwalika B, Haddad LB, Lakhi S, Onwubiko U, et al. Sustained effect of couples' HIV counselling and testing on risk reduction among Zambian HIV serodiscordant couples. Sex Transm Infect. 2017;93(4): 259-66.

78. Ngure K, Heffron R, Mugo NR, Celum C, Cohen CR, Odoyo J, et al. Contraceptive method and pregnancy incidence among women in HIV-1serodiscordant partnerships. AIDS. 2012;26(4):513-8.

79. Heffron R, Were E, Celum C, Mugo N, Ngure K, Kiarie J, et al. A prospective study of contraceptive use among African women in HIV-1 serodiscordant partnerships. Sex Transm Dis. 2010;37(10):621-8.

80. Haddad L, Wall KM, Vwalika B, Khu NH, Brill I, Kilembe W, et al. Contraceptive discontinuation and switching among couples receiving integrated HIV and family planning services in Lusaka, Zambia. AIDS. 2013; 27(Suppl 1):S93-103.

\section{Publisher's Note}

Springer Nature remains neutral with regard to jurisdictional claims in published maps and institutional affiliations.
Ready to submit your research? Choose BMC and benefit from:

- fast, convenient online submission

- thorough peer review by experienced researchers in your field

- rapid publication on acceptance

- support for research data, including large and complex data types

- gold Open Access which fosters wider collaboration and increased citations

- maximum visibility for your research: over $100 \mathrm{M}$ website views per year

At BMC, research is always in progress.

Learn more biomedcentral.com/submissions 